\title{
Quantitative Classification of Cerebellar Foliation in Cartilaginous Fishes (Class: Chondrichthyes) Using Three-Dimensional Shape Analysis and Its Implications for Evolutionary Biology
}

\author{
Kara E. Yopak ${ }^{a, b}$ Vitaly L. Galinsky ${ }^{c}$ Rachel M. Berquist ${ }^{c}$ Lawrence R. Frank ${ }^{c}$ \\ a UWA Oceans Institute and ${ }^{\mathrm{b}}$ School of Animal Biology, University of Western Australia, Crawley, W.A., Australia; \\ ${ }^{\complement}$ Center for Scientific Computation in Imaging, University of California, San Diego, La Jolla, Calif., USA
}

\section{Key Words}

Cerebellum · Comparative brain morphology · Brain

evolution · Spherical harmonics - Spherical wave

decomposition · Morphometry · Segmentation

\begin{abstract}
A true cerebellum appeared at the onset of the chondrichthyan (sharks, batoids, and chimaerids) radiation and is known to be essential for executing fast, accurate, and efficient movement. In addition to a high degree of variation in size, the corpus cerebellum in this group has a high degree of variation in convolution (or foliation) and symmetry, which ranges from a smooth cerebellar surface to deep, branched convexities and folds, although the functional significance of this trait is unclear. As variation in the degree of foliation similarly exists throughout vertebrate evolution, it becomes critical to understand this evolutionary process in a wide variety of species. However, current methods are either qualitative and lack numerical rigor or they are restricted to two dimensions. In this paper, a recently developed method for the characterization of shapes embedded within noisy, three-dimensional data called spherical wave decomposition (SWD) is applied to the problem of characterizing cerebellar foliation in cartilaginous fishes. The SWD method
\end{abstract}

provides a quantitative characterization of shapes in terms of well-defined mathematical functions. An additional feature of the SWD method is the construction of a statistical criterion for the optimal fit, which represents the most parsimonious choice of parameters that fits to the data without overfitting to background noise. We propose that this optimal fit can replace a previously described qualitative visual foliation index (VFI) in cartilaginous fishes with a quantitative analog, i.e. the cerebellar foliation index (CFI). The capability of the SWD method is demonstrated in a series of volumetric images of brains from different chondrichthyan species that span the range of foliation gradings currently described for this group. The CFI is consistent with the qualitative grading provided by the VFI, delivers a robust measure of cerebellar foliation, and can provide a quantitative basis for brain shape characterization across taxa.

(c) 2016 S. Karger AG, Basel

\section{Introduction}

The nervous system of cartilaginous fishes (class: Chondrichthyes; sharks, skates, rays, and holocephalans) represents an early, yet remarkably complete, stage in the evolution of the vertebrate brain [Yopak, 2012a, b]. Al-

\section{KARGER}

E-Mail karger@karger.com

www.karger.com/bbe
(C) 2016 S. Karger AG, Basel

$0006-8977 / 16 / 0874-0252 \$ 39.50 / 0$
Kara E. Yopak

UWA Oceans Institute and School of Animal Biology (M317)

University of Western Australia

35 Stirling Highway, Crawley, WA 6009 (Australia)

E-Mail kara.yopak.uwa@gmail.com 
though recent evidence confirms precursor structures in jawless fishes [Sugahara et al., 2016], the first true corpus cerebellum appeared in cartilaginous fishes, with many of the same cell types and organizational features conserved across all gnathostomes [reviewed by New, 2001; Montgomery et al., 2012]. Despite conservation of the cerebellar cytoarchitecture, there is still a high degree of variation in the size and convolution (or foliation) of this structure throughout vertebrate evolution [e.g. Nieuwenhuys and Nicholson, 1969; Northcutt, 1978; Smeets, 1998; Voogd and Glickstein, 1998; Butler and Hodos, 2005; Iwaniuk et al., 2006a]. However, as the functional role of this brain region is still an area of speculation [reviewed by Cordo et al., 1997; Highstein and Thach, 2002; Montgomery et al., 2012; Porrill et al., 2012; Baumann et al., 2014], the adaptive significance of this variation in size and shape across species is unclear [Northcutt, 1989; New, 2001].

Variation in the degree of cerebellar folia has received attention across a range of vertebrate clades [Larsell, 1967], including the valvula cerebellum of mormyrid fishes [e.g. Nieuwenhuys and Nicholson, 1969; Bell and Szabo, 1986; Striedter, 2005], and the cerebellum of birds [Senglaub, 1963; Larsell, 1967; Pearson and Pearson, 1976; Iwaniuk et al., 2006a, 2007], cartilaginous fishes [e.g. Yopak et al., 2007; Lisney et al., 2008; Puzdrowski and Gruber, 2009; Yopak et al., 2010b], and mammals [reviewed by Leto et al., 2015]. In birds, the degree of cerebellar foliation has been associated with an increase in body size [Senglaub, 1963; Pearson and Pearson, 1976], brain size, and cerebellum size [Iwaniuk et al., 2006a, 2007]. Similarly, mammalian isocortical gyrification closely correlates with both brain and isocortex size [Zilles et al., 1989; Carlson, 1991; Striedter, 2005]. Most studies have also asserted that cognitive and/or behavioral differences play a role in the evolution of the cerebellum, ranging from electrosensory-electromotor specialization in mormyrids to cognitive motor behaviors in birds and mammals, in addition to phylogenetic and allometric effects [Bell and Szabo, 1986; Demaerel, 2002; Sultan, 2005; Iwaniuk et al., 2006b, 2009; Sultan and Glickstein, 2007; Zhang et al., 2011; Hall et al., 2013].

In cartilaginous fishes, the corpus cerebellum varies substantially in size interspecifically [Northcutt, 1978; Yopak et al., 2007; Lisney et al., 2008; Montgomery et al., 2012; Yopak, 2012a], and it has been shown to scale hyperallometrically with the rest of the brain [Yopak et al., 2010b; Yopak, 2012a]. In addition to a high degree of variation in size, the corpus also has a high degree of variation in foliation and symmetry in this group [Northcutt, 1977, 1978; Puzdrowski and Leonard, 1992; Yopak et al., 2007;
Lisney et al., 2008; Puzdrowski and Gruber, 2009; Ari, 2011]. Indeed, the degree of variation in cerebellar foliation is more extreme than found in any other taxa, with variations ranging from a completely smooth cerebellar surface to deep, branched convexities and folds (fig. 1) [reviewed by Yopak, 2012a]. The morphological patterns of cerebellar foliation also vary intraspecifically [Puzdrowski and Gruber, 2009; Ari, 2011], and the degree of foliation of the corpus has been shown to vary with ontogeny [Yopak and Frank, 2009; Pose-Méndez et al., 2015].

To date, this extreme variation in corpus foliation has been assessed using a visual grading scheme termed the visual foliation index (VFI) [Yopak et al., 2007]. In brief, this method involves assigning a quantitative score (1-5) to characterize the length, depth, and number of folds in the cerebellum, with a grade of 1 corresponding to a smooth corpus surface and a grade of 5 corresponding to an extremely convoluted structure with deep, branched grooves, and distinctive cerebellar asymmetry. Based on this scheme, there is a clear trend towards higher levels of foliation occurring in species that occupy spatially complex habitats, such as corals reefs, or open oceanic habitats [Yopak et al., 2007; Lisney et al., 2008; Ari, 2011] and have highly active and/or maneuverable predation strategies [Lisney and Collin, 2006; Yopak et al., 2007], proprioception, and sensory acquisition [Yopak and Frank, 2009]. In contrast, low levels of foliation have been documented in less active benthic and deep-sea-dwelling benthopelagic species [Northcutt, 1978; Yopak et al., 2007, Lisney et al., 2008; Yopak and Montgomery, 2008], potentially related to more passive predation strategies and lower activity levels [Yopak and Montgomery, 2008; Yopak et al., 2010a] and a close association with the substrate [Northcutt, 1978; New, 2001]. Although the VFI provides the advantage of speed and the ability to assign a score based on photographs of tissue, enabling the rapid acquisition of large data sets [Yopak et al., 2007; Lisney et al., 2008], this method lacks mathematical resolution and is observer dependent, which can introduce subjectivity into the data set. As such, our understanding of the links between this evolutionary variation and allometric, behavioral, and cognitive parameters is limited to lowresolution, broad-scale differences often based on qualitative descriptions [e.g. Puzdrowski and Gruber, 2009]. What is required is an automated method that can mathematically assess finer-scale differences in foliation between species using high-resolution, three-dimensional (3D) digital data. 

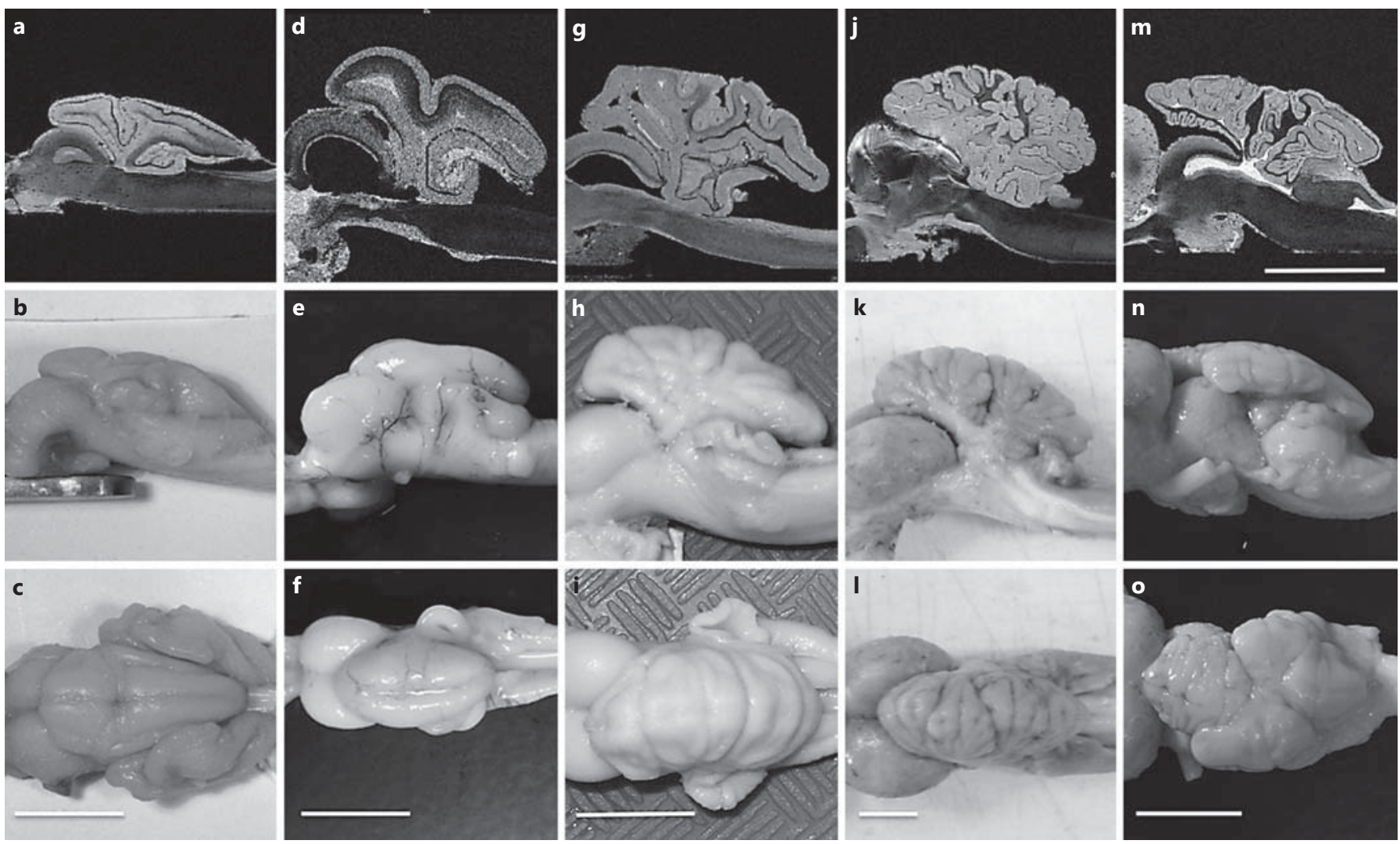

Fig. 1. Cerebellum from the five representative species of cartilaginous fishes examined in this study, i.e. $R$. binoculata (a-c), S. acanthias (d-f), M. californicus ( $\mathbf{g}-\mathbf{i})$, I. oxyrinchus $(\mathbf{j}-\mathbf{I})$, and S. tiburo (m-o), illustrating the five levels of the VFI (1-5) [Yopak et al., 2007]. For each species, each column shows a sagittal slice of the brain, acquired using MRI (a, $\mathbf{d}, \mathbf{g}, \mathbf{j}, \mathbf{m})$, and a lateral $(\mathbf{b}, \mathbf{e}, \mathbf{h}, \mathbf{k}, \mathbf{n})$ and dorsal view $(\mathbf{c}, \mathbf{f}, \mathbf{i}, \mathbf{I}, \mathbf{o})$ of the external cerebellar morphology. Scale bar $=1 \mathrm{~cm}$.

Standard approaches to characterization of complex shapes embedded within volumetric morphological data employ surface-based methods, such as a Fourier analysis [Brigham, 1974]. The procedure of doing a Fourier analysis on the spherical coordinates of a surface is called the spherical harmonic decomposition (SHD) method, and it has been shown to be useful for characterization of the global brain shape in humans [e.g. Chung et al., 2008a]. Preliminary studies have demonstrated potential applications of SHD for quantification of foliation in cartilaginous fishes beyond the visual grading scheme to more rigorously parameterize the fine-scale structural variation in the corpus cerebellum [Yopak and Frank 2007; Yopak et al., 2009]. However, the SHD method has limitations, as it requires user-guided segmentation of the structure to extract a cortical surface, which can be highly laborious [e.g. Yopak et al., 2009], subsequent inflation of the extracted surface into a sphere to produce a single-valued function of the radial coordinate, and then fitting of this surface with spherical harmonics up to some maximum order [Brechbuhler et al., 1995; Kazhdan et al., 2003]. Moreover, as demonstrated previously [Galinsky and Frank, 2014], this methodology is highly error prone because partial voluming (i.e. averaging of the intensities of different tissue types within a voxel) can blur tissue borders, complicating edge separation, resulting in topological defects in the inflated surface, which severely compromises the fitting process [Atkins and Mackiewich, 2000; Pham et al., 2000] and limits its utility for characterization of foliation. Galinsky and Frank [2014] recently addressed this general problem of shape characterization of 3D volumetric data and demonstrated that spherical wave decomposition (SWD) improves upon many of these limitations, as it facilitates automatic segmentation of high-contrast data and allows shape characterization of an entire volume, eliminating 
Table 1. Cerebellum volume range, VFI score $(1-5)$, and CFI for the five species examined in this study

\begin{tabular}{lcccc}
\hline Specimen & $\mathrm{n}$ & Cerebellar volume, $\mathrm{mm}^{3}$ & VFI score & CFI $\left(L_{\text {max }}\right)$ \\
\hline R. binoculata & 3 & $607.0 \pm 57$ & 1 & $41.7 \pm 1.5$ \\
S. acanthias & 3 & $698.2 \pm 208$ & 2 & $54.3 \pm 5.9$ \\
M. californicus & 3 & $607.0 \pm 460$ & 3 & $85.0 \pm 12.3$ \\
I. oxyrinchus & 2 & $1,534.4$ & 4 & $116.0 \pm 2.8$ \\
S. tiburo & 3 & $920.7 \pm 50.8$ & 5 & $150.7 \pm 14.0$ \\
\hline
\end{tabular}

Values are presented as means \pm SD unless otherwise stated. The VFI score was collated from Yopak et al. [2007] and Lisney et al. [2008]. For the CFI scores of individual specimens, see table 3 . the need for manual segmentation and subsequent surface inflation.

This study builds on previous work characterizing variation in foliation in these fishes [reviewed by Yopak, 2012a]. Here, we present a novel method for quantifying the foliation of the corpus cerebellum based on SWD of volumetric magnetic resonance imaging data. We have chosen 5 representative cartilaginous fish species that span the spectrum (1-5) of previously described VFI scores [Yopak et al., 2007]. This paper aims: (i) to demonstrate the validity of SWD to characterize broad variations in shape that are in concordance with the VFI but are mathematically obtained, (ii) to more rigorously parameterize cerebellar foliation by providing a foliation index scale with a wider dynamic range, thus identifying differences not calculable using the VFI, and ultimately (iii) to provide a new foliation index (cerebellar foliation index; CFI) based on the optimal fit, which is of greater statistical rigor than previously available schemes, using a root mean squared deviation (RMSD) criterion. Given that it is one of the first applications of 3D shape analysis technology to characterize shape variations in the chondrichthyan brain, we will evaluate the utility of SWD for quantification of cerebellar foliation, thus enabling multitaxon comparisons in future studies.

\section{Materials and Methods}

\section{Specimen Acquisition}

Brains from five species of cartilaginous fishes, representing each of the 5 levels of foliation from Yopak et al. [2007], were collected (table 1; fig. 1) in accordance with the ethical guidelines of the University of California, San Diego. Up to three replicates for each species were collected. Tissue was preserved in a range of aldehyde-based fixatives ( $10 \%$ formalin in $0.1 \mathrm{M}$ phosphate buffer or $4 \%$ paraformaldehyde in $0.1 \mathrm{M}$ phosphate buffer) and specimens were size-matched where possible. After removal of the meninges, blood vessels, choroid plexa, connective tissue, and sensory and cranial nerves, the brain tissue was prepared for imaging.

\section{Imaging and Segmentation}

After a period of fixation, brains were transferred to $1 \times \mathrm{PBS}+$ $0.01 \%$ sodium azide for at least 14 days to remove excess fixative before transfer to fresh $1 \times \mathrm{PBS}+0.01 \%$ sodium azide with the addition of $5 \mathrm{~mm}$ of the contrast agent Prohance ${ }^{\circledR}$ (Bracco Diagnostics Inc., Princeton, N.J., USA) for a further 7 days at $4^{\circ} \mathrm{C}$. Equilibration of the tissue in this contrast agent achieves a significant reduction in the longitudinal relaxation time (T1) of the sample and a corresponding increase in the SNR efficiency of our chosen data acquisition protocol [e.g. Berquist et al., 2012].

Brains were removed from the contrast agent solution and secured in a 50-ml Falcon tube for imaging. Experiments were performed on a Bruker 7-Tesla small-animal scanner, with a $22-\mathrm{cm}$ bore and gradient strengths of 46 gauss $/ \mathrm{cm}$. Magnetic resonance imaging (MRI) consisted of high-resolution $(100-150 \mu \mathrm{m}), \mathrm{T} 1-$ weighted anatomical acquisition using a gradient-recalled echo with no RF spoiling (well established for brain imaging) [Edelman et al., 1996] (fig. 1). High-resolution, T1-weighted anatomical imaging produces a high contrast between gray and white matter in chondrichthyan brains [e.g. Yopak and Frank, 2009], from which structural characteristics were derived. The pulse sequence parameters used for this study are shown in table 2 .

3D data of the whole brain were acquired from high-resolution MRI, and the corpus cerebellum was digitally segmented from the 3D data (fig. 2) using ITK-SNAP (Insight Segmentation and Registration Toolkit; www.itksnap.org) [Yushkevich et al., 2006]. These volumetric segmentations were then used as masks to delineate the corpus cerebellum from the whole-brain MRI data used to quantify cerebellar foliation.

\section{Quantification of Cortical Folding Using SWD}

The general approach to quantitative shape analysis is to describe the boundaries in a volumetric image in terms of well-defined mathematical functions that can parameterize the geometric complexity of the image. Traditional methods for fitting shapes to complex morphological data typically address the problem as one of fitting a surface in 3D, primarily because this approach has been considered more tractable computationally [Thompson et al., 1996a, b; Dale et al., 1999; Magnotta et al., 1999]. However, this 
Table 2. Pulse sequence parameters for the T1-weighted scans of the five species of cartilaginous fish imaged for this study

\begin{tabular}{|c|c|c|c|c|c|c|c|c|c|}
\hline \multirow[t]{3}{*}{ R. binoculata } & 1 & FLASH 3D & 15 & 22.3 & 13.0 & 0.1 & $1,024 \times 200 \times 350$ & 3 & 114 \\
\hline & 2 & FLASH 3D & 15 & 23.3 & 11.5 & 0.1 & $512 \times 350 \times 160$ & 11 & 219 \\
\hline & 3 & FLASH 3D & 15 & 25.9 & 12.9 & 0.1 & $700 \times 300 \times 300$ & 30 & 388 \\
\hline S. acanthias & $1^{\mathrm{a}}$ & FLASH 3D & 15 & - & - & 0.1 & $380 \times 256 \times 140$ & - & - \\
\hline \multirow[t]{3}{*}{ M. californicus } & 1 & FLASH 3D & 15 & 26.5 & 13.2 & 0.1 & $1,024 \times 256 \times 512$ & 4 & 91 \\
\hline & 2 & FLASH 3D & 15 & 25.9 & 12.9 & 0.1 & $700 \times 300 \times 300$ & 20 & 259 \\
\hline & 3 & FLASH 3D & 15 & 25.9 & 12.9 & 0.2 & $350 \times 150 \times 150$ & 6 & 39 \\
\hline \multirow[t]{2}{*}{ I. oxyrinchus } & 1 & FLASH 3D & 15 & 25.9 & 12.9 & 0.1 & $1,000 \times 500 \times 500$ & 7 & 302 \\
\hline & 2 & FLASH 3D & 15 & 26.5 & 13.2 & 0.1 & $1,024 \times 330 \times 260$ & 3 & 136 \\
\hline S. tiburo & 1 & FLASH 3D & 15 & 17.7 & 8.8 & 0.1 & $600 \times 350 \times 350$ & 3 & 53 \\
\hline
\end{tabular}

TR = Repetition time; TE = echo time; NEX = number of excitations. ${ }^{\text {a }}$ Full pulse sequence parameters are not available.

simplification comes at the cost of increased time and errors. In the SWD approach [Galinsky and Frank, 2014], the entire volume of data is fit. By extending the problem to $3 \mathrm{D}$, the expansion coefficients have the advantage of allowing characterization of the internal structure simultaneously with the overall shape. Because they are not surface based, there is no need to fix topological discrepancies or to provide surface-based segmentation first. Thus, this approach offers a more complete description of noisy volumetric data, and is it also more efficient to compute.

SWD characterizes volumetric data $f(r, \theta, \varphi)$ in terms of the three spherical coordinates $(r, \theta, \varphi)$, the radius $(r)$, and the polar and azimuthal angles $(\theta, \varphi)$. This characterization takes the form:

$$
f(r, \theta, \varphi)=\sum_{n=1}^{\infty} \sum_{l=0}^{\infty} \sum_{m=-l}^{l} f_{l m n} R_{l n}(r) Y_{l}^{m}(\theta, \varphi),
$$

where the angular characteristics of the data are described by spherical harmonics $Y_{l}^{m}(\theta, \varphi)$ (given in equations 8 and 9) and the radial characteristics by the functions $R(r)$, which can be expressed in terms of spherical Bessel functions [Chung et al., 2009] (given in equations 10-12). The data are thus represented by the sum of the product of these functions at different orders $(n, l)$ up to the maximum orders $\left\{L_{\max }, N_{\max }\right\}$. The higher the orders, the greater the spatial detail the functions describe. The coefficients $f_{l m n}$ determine the contribution from each of the functions. These coefficients are the unknowns of the problem, which need to be determined, and are the output of the fitting procedure. Thus, the model order problem is determining the optimal choice of $\left\{L_{\max }, N_{\max }\right\}$. The optimal model order is one that is just large enough to capture the true spatial detail in the data, which becomes a metric for the complexity of the data. In the absence of noise, increasing the model order beyond that necessary to fit the data gives a false measure of the data complexity. In the presence of noise (which is always present in MRI data, for example), increasing the model order increases the fitting of the very high spatial variations caused by the noise. This 'fitting of the noise' also gives a false measure of the data complexity. In our particular context, the optimal model order will be used as our foliation index, as discussed below.

Equation 1 is a representation of the data in terms of the unknown coefficients $f_{l m n}$ and model functions. The goal is to determine these coefficients, which can be done by 'inverting' equation 1 to give an expression for the coefficients in terms of the data and the model functions:

$$
f_{l m n}=\int_{0}^{a} \int_{0}^{\pi} \int_{0}^{2 \pi} f(r, \theta, \varphi) R_{n l}(r) Y_{l}^{m}(\theta, \varphi) r^{2} d r \sin \theta d \theta d \varphi .
$$

The relative orientation of the volumetric data (e.g. the cerebellum) to an external coordinate system (e.g. the MRI scanner) is irrelevant to the analysis, and so it is useful to construct a rotationally invariant quantity, or signature, that still captures the relative magnitude of the coefficients but mitigates any relationship with the external coordinate system. Such a rotationally invariant signature can be calculated directly from the coefficients $f_{l m n}$ by taking the squared absolute value (i.e. the $L_{2}$-norm) of all the $f_{l m n}$ at each $l$ and $n$ :

$$
S_{l n}=\sum_{m=-1}^{l}\left|f_{l m n}\right|^{2} \text {. }
$$

The resulting signature, represented as a two-dimensional (2D) grid of size $L_{\text {max }} \times N_{\text {max }}$, where $N_{\text {max }}$ is the number of spherical Bessel functions used in radial expansion (see equations 10-12) and it is purely in frequency space.

\section{The Foliation Index}

We desire a single quantitative index that can serve as a quantitative analog of the VFI previously put forth by Yopak et al. [2007]. This should be related to the optimal expansion degrees $\left\{\hat{L}_{\text {max }}, \hat{N}_{\text {max }}\right\}$ of the SWD transform. By 'optimal' we mean the degrees that produce the best fit to the data using an RMSD criterion. Thus, $\left\{\hat{L}_{\text {max }}, \hat{N}_{\text {max }}\right\}$ are the degrees $\left\{L_{\text {max }}, N_{\text {max }}\right\}$ for which SWD provides the closest representation of the data. To estimate how well SWD with the preselected degrees $L_{\max }$ and $N_{\max }$ will repre- 


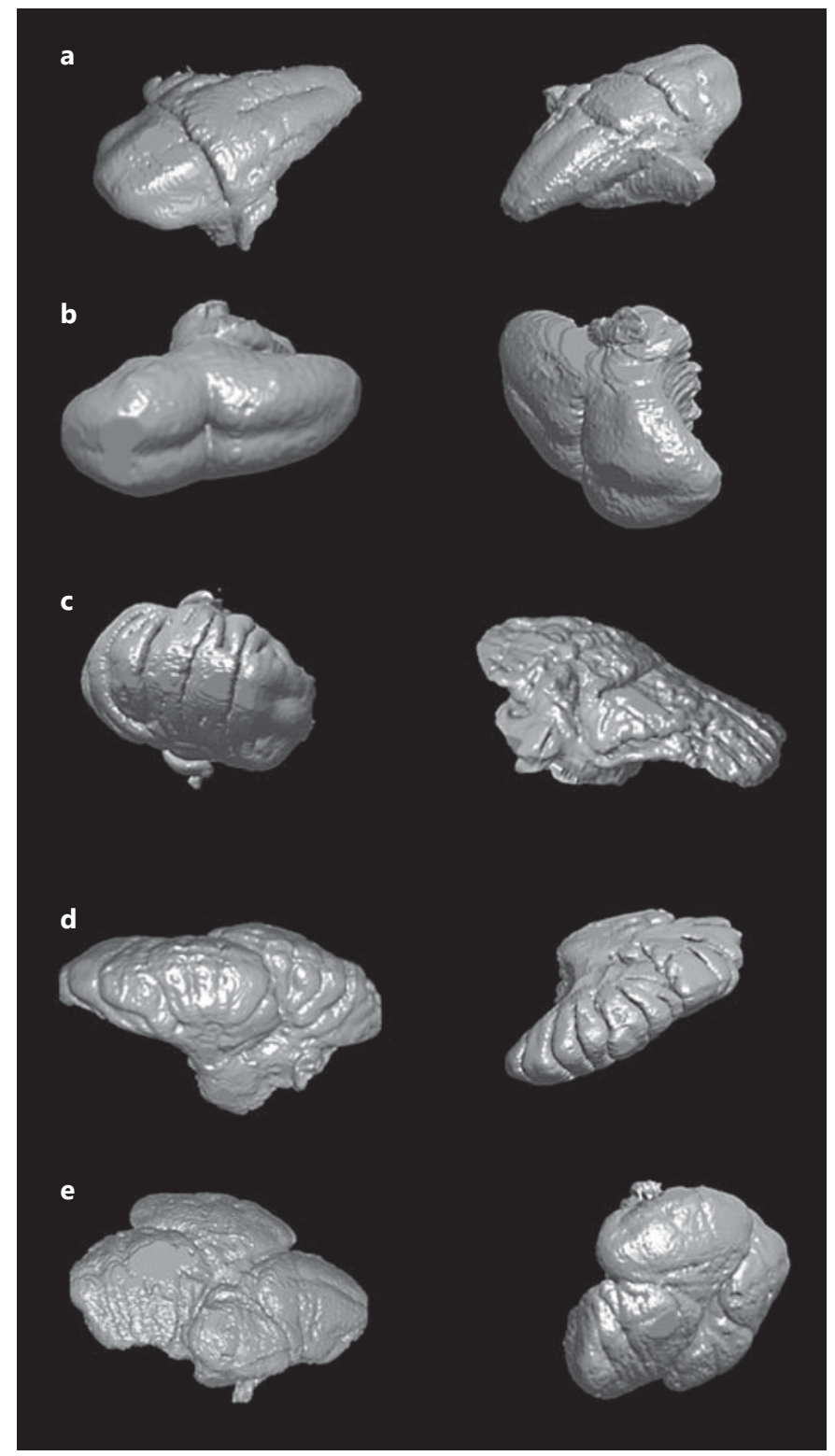

Fig. 2. Representative $3 \mathrm{D}$ volume renderings of the cerebellum from five species of cartilaginous fishes examined in this study. These surfaces were automatically extracted from the grey matter from volumetric data and then decomposed into shape coefficients defined over the entire data volume in order to determine the optimal fitting degree for R. binoculata (a), S. acanthias (b), M. californicus (c), I. oxyrinchus (d), and S. tiburo (e). Volumes are not to scale.

sent any particular data set, the RMSD can be used. Although, in SWD, the angular and radial degrees can be changed independently, the number of zeros of the spherical Bessel function that fall inside the sphere of radius $a$ corresponds to the number of zeros in latitudinal or longitudinal directions when $L_{\max } \sim N_{\max }$. Hence, for the purpose of finding the optimal degree order, we will assume that $N_{\max }=L_{\max }$. This allows us to define the foliation index as a single parameter - the optimal angular expansion degree $\hat{L}_{\text {max }}[\mathrm{Ga}$ linsky and Frank, 2014].

The distribution of the Fourier coefficients $f_{l m n}$ can be approximated to follow a normal distribution $N\left(\mu_{l m m}, \sigma_{l}^{2}\right)$ with equal variance $\sigma_{l}$ within the same degree [Chung et al., 2007]. This corresponds to the following $k-1$ degree model:

$$
f_{k-1}\left(r_{i}\right)=\sum_{n=1}^{k-1 k=1} \sum_{l=0}^{l} \sum_{m=-l}^{l} e^{-l(l+1) t} \mu_{l m n} R_{l n}\left(r_{i}\right) Y_{l}^{m}\left(\theta_{i}, \varphi_{i}\right)+\varepsilon\left(r_{i}\right),
$$

where $\varepsilon$ is a zero mean isotropic Gaussian random field. Then, we can test whether increasing the degree of the model above $k-1$ is statistically significant by testing the null hypothesis:

$$
H_{0}: \mu_{l m n}=0 \text { for } l=k, n=k,|m| \leq k .
$$

For construction of the test statistic, we used the residual sum of squares (RSS) for the $(k-1)$ degree model $f_{k-1}$, that is:

$$
R R R_{k-1}=R S S\left(f_{k-1}\right)=\sum_{i=1}^{N}\left(f\left(r_{i}\right)-f_{k-1}\left(r_{i}\right)\right)^{2} .
$$

The test statistic used to account for different numbers of 'groups' and 'observations' [Galinsky and Frank, 2014] is:

$$
F=\frac{\left(R S S_{k-1}-R S S_{k}\right) /\left(3 k^{2}+k\right)}{R S S_{k-1} /\left(N-(k-1)^{2} k\right)} \sim F_{3 k^{2}+k, N-(k+1)^{2} k} .
$$

The resulting distribution is the $F$ distribution, with different values of degrees of freedom $\left[(3 k+1) k\right.$ and $\left.N-k(k+1)^{2}\right]$. The optimal SWD degree can be obtained by computing the $F$ statistic for each degree $k$ up to the point when the corresponding $\mathrm{p}$ value becomes bigger than the prespecified significance $\alpha$.

\section{Methods for Computing SWD}

We describe the angular characteristics of the volumetric data for the SWD analysis as follows. The spherical harmonics $Y_{l}^{m}(\theta, \varphi)$ of degree $l$ and order $m$ are expressed using associated Legendre polynomials $P_{m}^{m}$ of order $m$ as:

$$
Y_{l}^{m}(\theta, \varphi)=c_{l, m} P_{l}^{m}(\cos \theta) e^{-i m \theta},
$$

where $c_{l, m}$ is the normalization constant:

$$
c_{l, m} \sqrt{\frac{2 l-1}{4 \pi}} \frac{(l-m) !}{(l+m) !} .
$$

We describe the radial characteristics of the volumetric data for the SWD analysis as follows. The data are assumed to be defined by a sphere of radius $a$. The radial component $R_{l n}(r)$ of equation 1 can be expressed in terms of the spherical Bessel function $j_{l}$ as:

$$
R_{l n}(r)=\frac{1}{\sqrt{N_{l n}}} j_{l}\left(k_{l n} r\right) .
$$

The normalization constants $N_{l n}$, as well as the discrete spectrum wave numbers $K_{l n}$, are determined by the choice of boundary conditions. For the Dirichlet boundary condition, i.e. $f(r, \theta, \varphi) \equiv 0$ for $r \geq a$, they can be expressed as:

$$
N_{l n}=\frac{a^{3}}{3} j_{l+1}^{2}\left(l_{l n} r\right)
$$

where $\left\{x_{l n}\right\}$ are ordered for $n>1$ zeros of the spherical Bessel function $j_{l}(x)$. With this choice of the discrete spectral numbers $k_{l n}$ and 


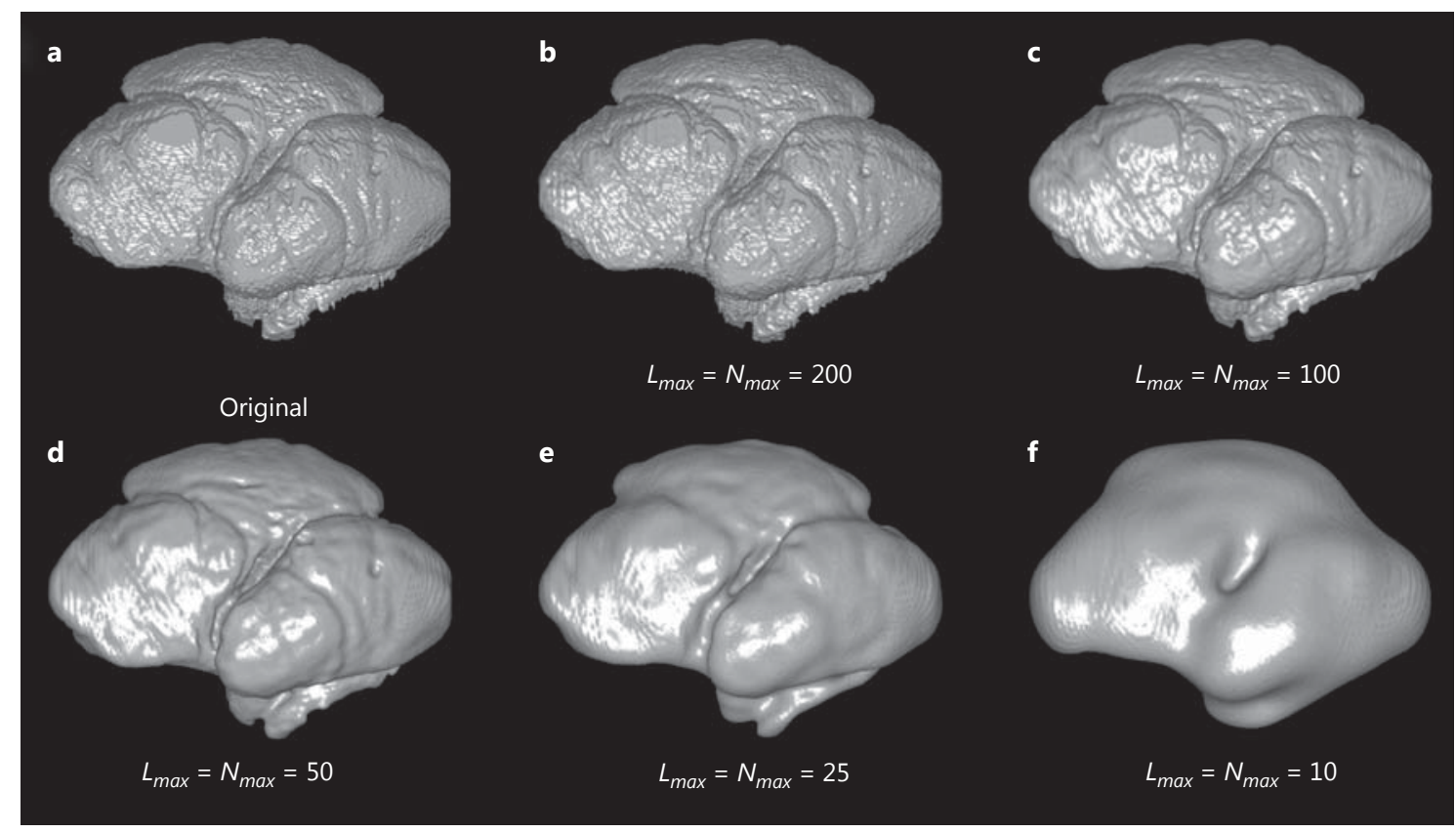

Fig. 3. Series of 3D brain reconstructions of $S$. tiburo, obtained with different degrees of SWD (different $L_{\text {max }}$ and $N_{\max }$ parameters) showing the original brain segmentation (a) and decreasing $L_{\max }$ and $N_{\max }$ from 200 to 10 (b-f).

the normalization constants $N_{l n}$, the orthonormality conditions for $R_{\ln }(r)$ read:

$$
\int_{0}^{a} R_{l n} R_{l n^{\prime}}, r^{2} d r=\delta_{n n^{\prime}}
$$

\section{Shape Analysis}

The typical processing workflow to generate foliation indices involves transforming the original MR volumetric data sets into a high-degree SWD expansion (typically with $\left\{\hat{L}_{\max }, \hat{N}_{\max }\right\}$ of the order of 300) and then restoring the volumetric data using an undersampled SWD representation. The restoration is performed starting with initially low values of $\left\{\hat{L}_{\max }, \hat{N}_{\max }\right\}$ (usually $\sim 10$ ), progressively increasing the degrees until a minimum of an RMSD is found. Thus, the CFI is now defined as the optimal $L_{\max }$.

Each image data set took between $20 \mathrm{~min}$ and $1 \mathrm{~h}$ to process, depending on the resolution and complexity, on a single-thread Intel ${ }^{\circledR}$ Core $^{\mathrm{TM}}$ i7-4930K CPU $(3.40 \mathrm{GHz})$. The $\mathrm{C}++$ code for the algorithms used in this shape analysis method is available upon request and runs on all platforms.

\section{Results}

The five species of cartilaginous fishes examined in this study exhibit wide variation in cerebellar convolution and symmetry (fig. 1,2). According to the VFI of Yopak et al. [2007], cerebellar complexity ranges from little to no foliation of the corpus (Raja binoculata, VFI = 1) to min- imal foliation, with shallow grooves running parallel to one another without branching (Squalus acanthias, $\mathrm{VFI}=2$ ), to moderate foliation, with shallow to moderate grooves and slight branching (Mustelus californicus, $\mathrm{VFI}=3$ ), to a very foliated corpus, with moderate to deep branched grooves and mild cerebellar asymmetry (Isurus oxyrhinchus, VFI = 4), to extreme foliation of the corpus, with deep, branched grooves, and a distinctive cerebellar asymmetry (Sphyrna tiburo, VFI $=5$ ).

We have demonstrated the successful application of SWD for quantification of cerebellar foliation in cartilaginous fishes beyond this visual grading scheme. We obtained a quantitative index score, referred to as the CFI, related to the optimal expansion degrees $\left\{\hat{L}_{\text {max }}, \hat{N}_{\text {max }}\right\}$ of the SWD transform (table 1; fig. 3), that can serve as a quantitative analog of the VFI previously put forth by Yopak et al. [2007]. For each cerebellar surface (fig. 2), the degrees $\left\{L_{\max }, N_{\max }\right\}$ for which the SWD provides the closest representation of the data were statistically significant using an RMSD criterion (table 3; fig. 4).

According to the SWD transform, the degree of 3D shape complexity (and thus foliation) varied considerably among the 5 species examined (fig. 5). The broad pattern of results from the SWD transform was very similar to the VFI (table 1), and there was a highly significant correla- 
Table 3. SWD method output for all specimens within each of the species representing the VFI scores (1-5) after Yopak et al. [2007] (see table 1)

\begin{tabular}{|c|c|c|c|c|c|c|}
\hline Specimen & Replicate & $L_{\max }$ & $\mathrm{RMSD}_{\mathrm{L}}, \times 10^{-5}$ & $\mathrm{RMSD}_{\mathrm{L}}-\mathrm{RMSD}_{\mathrm{L}-1}, \times 10^{-5}$ & Voxels, $\times 10^{5}$ & Voxel resolution, $\mathrm{mm}$ \\
\hline \multirow[t]{2}{*}{ R. binoculata } & 1 & 43 & 9.7646 & 6.7997 & 80.3841 & 0.8838 \\
\hline & 2 & 42 & 36.2451 & 5.1319 & 17.7305 & 0.9924 \\
\hline \multirow[t]{3}{*}{ S. acanthias } & 1 & 50 & 42.6697 & 14.4432 & 4.4890 & 1.3769 \\
\hline & 2 & 52 & 5.6606 & 11.9318 & 33.1695 & 1.0000 \\
\hline & 3 & 61 & 5.2101 & 2.7070 & 34.3000 & 1.0000 \\
\hline M. californicus & 3 & 94 & 41.0873 & 14.4840 & 1.0397 & 2.0000 \\
\hline \multirow{2}{*}{ I. oxyrinchus } & 1 & 114 & 3.0791 & 3.9427 & 52.3745 & 1.0000 \\
\hline & 2 & 118 & 5.8261 & 1.6428 & 58.3870 & 0.8950 \\
\hline \multirow[t]{2}{*}{ S. tiburo } & 1 & 150 & 1.7693 & 2.0016 & 96.2560 & 1.0000 \\
\hline & 2 & 137 & 3.1923 & 2.0895 & 45.2900 & 1.0000 \\
\hline
\end{tabular}

$L_{\text {max }}$ is the optimal degree of expansion of the SWD transform that produces the best fit for the cerebellum using an $\mathrm{RMSD}_{\mathrm{L}} \mathrm{crite}$ rion. $\mathrm{RMSD}_{\mathrm{L}}-\mathrm{RMSD}_{\mathrm{L}-1}$ shows the absolute change in $\mathrm{RMSD}$ between $l=L_{\text {max }}$ and $l=L_{\text {max }}-1$. The values of the cumulative probability at $l=L_{\text {max }}$ for each sample are highly significant $(\mathrm{p}<0.001)$.

tion between the rank position of each specimen, ranked from 1 to 14 on the basis of its corresponding VFI or optimal $L_{\max }$ score ( $\mathrm{rs}=0.981, \mathrm{n}=14, \mathrm{p}<0.0001$; Spearman's rank, 2-tailed). However, the SWD provided a characterization of foliation across a wider dynamic range than the VFI. The new CFI, based on the optimal $L_{\max }$ score, ranged from a score of 40 ( $R$. binoculata) to a score of 165 (S. tiburo), with a median CFI of 80.5 (within the range of M. californicus; table 3; fig. 4). The standard deviations of CFI scores within a species examined in this study were within $14 \%$ (table 1 ), which may reflect variations in 3D image quality and contrast or intraspecific variation in corpus foliation.

\section{Discussion}

Although variation in cerebellar foliation has been documented across a range of taxa [e.g. Northcutt, 1978; Bell and Szabo, 1986; Iwaniuk et al., 2006a, 2007; Yopak et al., 2007], the drivers of this characteristic are unclear. It has been proposed that an increase in cerebellar foliation accommodates an increase in cerebellar surface area (and thus an increase in cell density) within a constrained volume [Striedter, 2005]. Higher levels of cerebellar foliation are likely to be, to some extent, associated with enhanced cerebellar function [Welker, 1990; Sudarov and
Joyner, 2007], thus enabling increased behavioral complexity [Iwaniuk et al., 2007; Sultan and Glickstein, 2007]. However, to date, the links between cerebellar foliation and complex behavioral repertoires in cartilaginous fishes have been restricted to observational descriptions [Northcutt, 1978; New, 2001] and a visual grading method [Yopak et al., 2007; Lisney et al., 2008], which fails to fully parameterize the structural variation that exists across this clade.

Here, we present a novel method to quantify the variation in cerebellar foliation in 5 representative species of cartilaginous fishes, based on SWD of the data [Galinsky and Frank, 2014]. This method directly analyzes the entire data volume, obviating the segmentation, inflation, and surface fitting steps, significantly reducing the computational time and eliminating topological errors while providing a more detailed quantitative description based upon a more complete theoretical framework of volumetric data. Here, we demonstrate that the SWD method can efficiently quantify variations in complexity in the chondrichthyan cerebellum and has some advantages over current visual-scoring methods [Yopak et al., 2007], as it is automated, thus removing bias due to subjectivity, and produces an index over a wider dynamic range, enabling quantification of fine-scale differences in foliation not detectable by previous schemes. Further, the new foliation index provides greater statistical rigor, as SWD calculates 


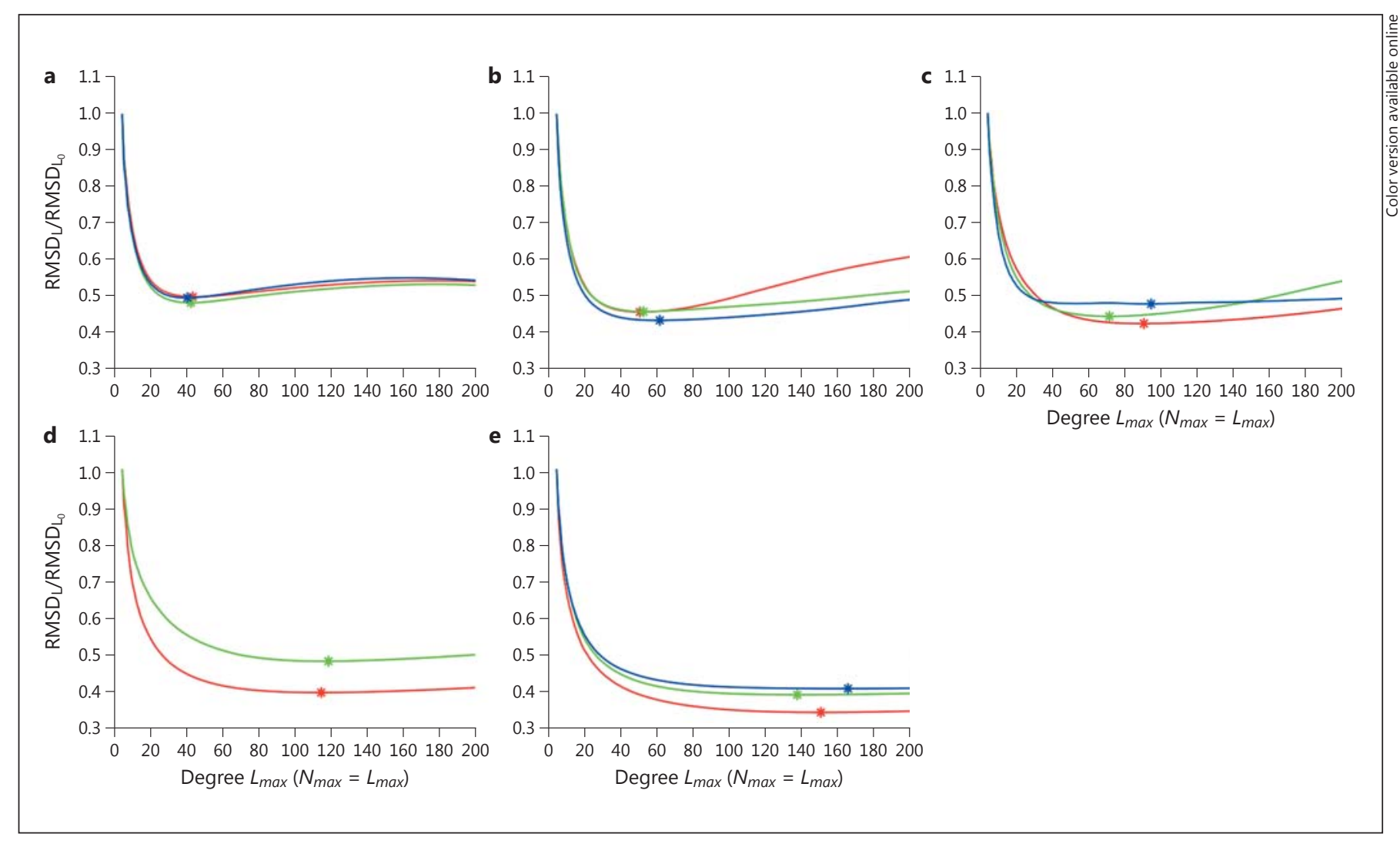

Fig. 4. CFI score, as described by the optimal $L_{\max }$ value for each specimen (denoted on each graph by an asterisk), acquired using the SWD method, for R. binoculata (a), S. acanthias (b), M. californicus (c), I. oxyrinchus (d), and $S$. tiburo (e). The optimal $L_{\max }$ describes the degrees that produce the best fit to the data using an

the optimal fit of the data (now the CFI score) using an RMSD criterion.

\section{Applications of Bioimaging and Shape Analyses in Comparative Biology}

MRI is rapidly emerging as a unique tool for noninvasive acquisition of high-resolution, 3D, digital data of soft-tissue structures, which facilitates long-term digital archiving of rare anatomical collections [e.g. Corfield et al., 2008a; Berquist et al., 2012; Zeigler et al., 2014]. Recent studies have demonstrated the utility of MRI for comparative brain morphology in marine mammals [Marino et al., 2001a, b; Montie et al., 2008; Oelschlager et al., 2010; Berns et al., 2015], birds [Corfield et al., 2008a, b], reptiles [Hoops et al., 2014], teleosts [Van der Linden et al., 2004; Ullmann et al., 2010a-c], and cartilaginous fishes [Yopak and Frank, 2007; Pradel et al., 2009; Yopak et al., 2009, 2010a], which provides invaluable data on the size and
RMSD criterion. Thus, $\left\{\hat{L}_{\max }, \hat{N}_{\max }\right\}$ are the degrees $L_{\max }, N_{\max }$ for which SWD provides the closest representation of the data. Higher $L_{\text {max }}$ scores indicate higher levels of cerebellar surface complexity. For average $L_{\max }$ values, see table 1 . For $L_{\max }$ values for each specimen, see table 3 . precise anatomical position of major neuroanatomical features and allows noninvasive assessment of specimens. The majority of comparative neuroanatomical studies in nonmammalian vertebrates utilizing MRI have acquired 3D information for the purposes of assessment of the whole brain volume or the volume of major brain regions across taxa [Marino et al., 2003; Kaufman et al., 2005; Oelschlager et al., 2008; Yopak and Frank, 2009; Ullmann et al., 2010b]. However, to date, few have explored the utility of MR data for quantification of variations in surface structure complexity [Yopak and Frank, 2007; Yopak et al., 2009].

Previous assessments of variation in cortical and/or cerebellar folding in other vertebrates have often been constrained to $2 \mathrm{D}$ analyses. A very comprehensive study on variations in both the degree of foliation [Iwaniuk et al., 2006a] and the size of the cerebellar folia [Iwaniuk et al., 2007] in 96 species of birds was quantitatively assessed 


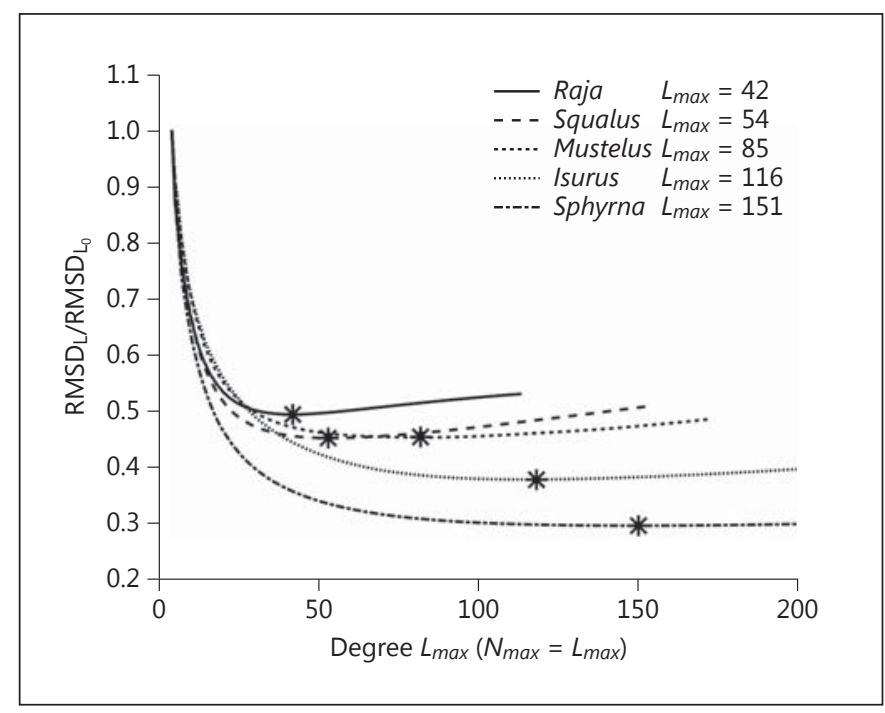

Fig. 5. Average CFI score, as described by the optimal $L_{\text {max }}$ value, for each species (denoted on each graph by an asterisk), acquired using the SWD method, for R. binoculata, S. acanthias, M. californicus, $I$. oxyrinchus, and $S$. tiburo. The optimal $L_{\max }$ describes the degrees that produce the best fit to the data using a RMSD criterion. Thus $\left\{\hat{L}_{\text {max }}, \hat{N}_{\text {max }}\right\}$ are the degrees $L_{\text {max }}, N_{\text {max }}$ for which SWD provides the closest representation of the data. For the $L_{\text {max }}$ values of each specimen, see table 3 .

from 2D histological sections, with comparisons between foliation and ecological parameters. These comparisons were made possible by assuming a bilateral symmetry of the cerebellum, with respect to the midline, thus making measurements on mid-sagittal sections [e.g. Senglaub, 1963; Larsell, 1967; Matochik et al., 1991] representative of the entire structure [Sultan, 2005; Iwaniuk et al., 2006a, 2007]. However, the chondrichthyan cerebellum is known to vary greatly in terms of both convolution and symmetry, with the highest degrees of cerebellar asymmetry documented in species with the highest degree of foliation (fig. 1m-o) [reviewed in Yopak, 2012a]. Indeed, this asymmetry, characterized by the orientation of the caudal lobule, is known to vary even intraspecifically [Voorhoeve, 1917; Puzdrowski and Leonard, 1992; Puzdrowski and Gruber, 2009; Ari, 2011]. Thus, a calculated CFI from a midline section will not provide a true measure of foliation in this group, not just between species but even within a single species, and thus an alternate method is needed to characterize this variation.

Quantitation of these complex anatomical details in an automated computational procedure is exceedingly difficult and remains an active area of research, which is generally termed shape analysis [Brechbuhler et al., 1995;
Kazhdan et al., 2003]. Most standard approaches to shape analysis simplify the problem from the outset by reducing it to the analysis of surfaces [Thompson et al., 1996a, b; Dale et al., 1999; Magnotta et al., 1999], which is both theoretically and computationally much simpler, at least in principal. This approach is carried out by an initial segmentation of a surface of interest and a subsequent inflation of this surface to satisfy the uniqueness or stability of subsequent surface-fitting algorithms. While these surface-based methods are ubiquitous, presumably because of the assumed reduction in complexity resulting from the reduced dimensionality [Chung et al., 2007, 2008a, b], they require manual segmentation prior to fitting and the computationally intensive inflation process, the latter of which is a significant source of error due to the creation of topological defects [see Galinsky and Frank, 2014].

A recently developed, fully 3D method based on SWD has been applied to entire volumetric data sets of the human brain [Galinsky and Frank, 2014]. This study showed that a fully developed theory of 3D shape analysis yields an efficient and robust computational algorithm that can rapidly quantitate 3D structures from volumetric digital data in terms of well-defined coefficients of mathematical functions in nonmammalian brains. This procedure provides estimates of the fit coefficients and defines the error in these estimates and the statistical significance of the estimated coefficients [Galinsky and Frank, 2014]. This, in turn, provides a quantitative assessment of cerebellar surface complexity.

\section{Functional and Evolutionary Implications}

Cartilaginous fishes occupy a basal position in the evolutionary tree of gnathostomes, which is characterized by a number of remarkable evolutionary advances. Of particular note is the emergence of the full vertebrate brain archetype and the first true corpus cerebellum [reviewed by Striedter, 2005; Montgomery et al., 2012; Pose-Méndez et al., 2016] that coincided with the evolution of jaws and paired fins [Northcutt and Gans, 1983; Depew and Olsson, 2008]. However, the degree to which variations in the size and complexity of the cerebellum are related to behavioral and motor complexity across vertebrates, and the basic principles governing the evolution of enhanced cognitive function, is currently not fully understood.

An increase in the surface area of the cerebellum via an increase in cerebellar foliation is assumed to be a mechanism for increasing the length of the Purkinje cell layer [Iwaniuk et al., 2006a]. This is comprised of a 1- to 2-cell layer made up of Purkinje cells, which represents the main motor output pathway of the cerebellum in most 
vertebrates [Voogd and Glickstein, 1998]. From a functional perspective, an increase in Purkinje cell numbers is likely to result in an increase in cerebellar processing capacity, thus facilitating the acquisition of a more complex functional circuitry [Welker, 1990; Sudarov and Joyner, 2007]. Based on the VFI [Yopak et al., 2007], it has been reported that the number of cerebellar folia increases with both absolute and relative cerebellar sizes in chondrichthyans [Yopak et al., 2010b] in a manner analogous to avian cerebellar foliation [Senglaub, 1963; Iwaniuk et al., 2006a] and mammalian cortical gyrification, which is correlated with both brain and isocortex size [Zilles et al., 1989; Striedter, 2005]. Yopak et al. [2010b] suggested that cerebellar foliation may be an identifying feature of highly encephalized brains and that an increased cerebellar surface area (via an increase in cerebellar foliation) may be linked to more multifaceted motor tasks associated with habitat complexity [e.g. Yopak et al. 2007; Lisney et al., 2008]. However, these current correlations are based solely on visual assessment of the corpus, and the links between foliation and behavior can only improve with more finely resolved data.

The SWD method provides a more robust characterization of the cerebellum in cartilaginous fishes, with a new, mathematically obtained CFI that spans a much wider dynamic range than was previously available [Yopak et al., 2007]. In the future, when applied across a broad multitaxon data set, SWD will allow a better-resolved, phylogenetically informed comparative analysis of cerebellar foliation and the allometric and ecological parameters that may be driving brain structure variation [e.g. Yopak, 2012a; Yopak and Lisney, 2012; Yopak et al., 2015]. Further, as the true degree of intraspecific variation in foliation is currently unknown [Puzdrowski and Gruber, 1992; Yopak and Frank, 2009; Ari, 2011], SWD can provide a powerful means to assess variability within a single species, for quantifying behavioral and/or cognitive differences between individuals throughout ontogeny or between populations, to better assess the links between cerebellar foliation and behavioral specializations.
A previous demonstration of this method on high-resolution data [Galinky and Frank, 2014] of the highly foliated human brain demonstrated the ability to model the fine folding patterns in even the most highly foliated specimens. Thus, the ability of the SWD to quantify the entirety of the volumetric data in terms of numerical coefficients for a well-defined set of spherical basis functions provides a substantially more rigorous and flexible methodology. Moreover, as digital data gets increasingly accurate with high spatial resolution, this will significantly enhance our ability to detect subtle but important morphological variations too complex to be ascertained, much less quantified, by the human eye.

\section{Conclusions}

Characterization of complex shapes embedded within volumetric data is an important step in a wide range of applications in comparative neuroanatomy. Here, we demonstrate the ability of the SWD method to determine the optimal fitting degree $\left(L_{\max }\right)$ for the cerebellum, which serves as a new mathematically defined CFI for cartilaginous fishes. We envisage that a wider application of this technique across a data set of taxonomically and ecologically diverse species in the future will truly parameterize the variation in foliation in this group, enabling new insights into the link between form and function.

\section{Acknowledgments}

L.R.F., K.E.Y., and R.M.B. were supported by NSF grants EF0850369 and DBI-1143389. L.R.F., V.L.G., and R.M.B. were also supported by NSF grants DBI-114726045, PHY-1201238, and ACI-1440412, and by NIH grant R01MH096100. K.E.Y. was supported by a Sir Keith Murdoch Fellowship from the AmericanAustralian Association, an Australian Research Council Discovery Project Grant, and funds from S.P. Collin during the writing of this paper.
References
Ari C (2011): Encephalization and brain organization of mobulid rays (Myliobatiformes, Elasmobranchii) with ecological perspectives. Open Anat J 3:1-13.

Atkins M, Mackiewich B (2000): Fully automated hybrid segmentation of the brain; in Bankman IN (ed): Handbook of Medical Image Processing and Analysis. Burlington, Academic Press, pp 171-183.
Baumann O, Borra RJ, Bower JM, Cullen KE, Habas $\mathrm{C}$, Ivry RB, Leggio M, Mattingley JB, Molinari M, Moulton EA, Paulin MG, Pavlova MA, Schmahmann JD, Sokolov AA (2014): Consensus paper: the role of the cerebellum in perceptual processes. Cerebellum 14:197220. 
Bell CC, Szabo T (1986): Electroreception in mormyrid fish: central Anatomy; in Bullock $\mathrm{TH}$, Heiliegenberg W (eds): Electroreception. New York, Wiley.

Berns G, Cook P, Foxley S, Jbabdi S, Miler K, Marino L (2015): Diffusion tensor imaging of dolphin brains reveals direct auditory pathway to temporal lobe. Proc Biol Sci 282: 20151203.

Berquist R, Gledhill K, Peterson M, Doan A, Baxter G, Yopak K, Kang N, Walker H, Hastings P, Frank L (2012): The Digital Fish Library: digitizing, databasing, and documenting the morphological diversity of fishes with MRI. PLoS One 7:e34499.

- Brechbuhler C, Gerig G, Kubler O (1995): Parametrization of closed surfaces for 3-D shape description. Comput Vis Image Underst 61: 154-170.

Brigham E (1974): The Fast Fourier Transform. Englewood Cliffs, Prentice-Hall Inc.

Butler AB, Hodos W (2005): Comparative Vertebrate Neuroanatomy. New York, Wiley.

-Carlson M (1991): Ontogenetic and phylogenetic perspectives on somatic sensory cortex and tactile function; in Franzen O, Westman J (eds): Information Processing in the Somatosensory System. Hampshire, Macmillan Press, pp 177-192.

-Chung MK, Dalton KM, Davidson RJ (2008a): Tensor-based cortical morphometry via weighted spherical harmonic representation. IEEE Trans Med Imaging 28:1143-1151.

-Chung MK, Dalton KM, Shen L, Evans AC, Davidson RJ (2007): Weighted Fourier series representation and its application to quantifying the amount of gray matter. IEEE Trans Med Imaging 26:566-581.

Chung MK, Harley R, Dalton KM, Davidson RJ (2008b): Encoding cortical surface by spherical harmonics. Stat Sin 18:1269-1291.

Chung MK, Wu Y-C, Alexander AL (2009): 3D eigenfunction expansion of sparsely sampled $2 \mathrm{D}$ cortical data. IEEE Int Symp Biomed Imaging 1-2:113-116.

Cordo PJ, Bell CC, Harnad S (eds) (1997): Motor Learning and Synaptic Plasticity in the Cerebellum. Cambridge, Cambridge University Press.

-Corfield JR, Wild JM, Cowan BR, Parsons S, Kubke MF (2008a): MRI of postmortem specimens of endangered species for comparative brain anatomy. Nat Protoc 3:597-605.

-Corfield JR, Wild JM, Hauber ME, Parsons S, Kubke MF (2008b): Evolution of brain size in the Palaeognath lineage, with an emphasis on New Zealand ratites. Brain Behav Evol 71:8799.

Dale A, Fischl B, Sereno M (1999): Cortical surface-based analysis. 1. Segmentation and surface reconstruction. Neuroimage 9:179-194.

Demaerel P (2002): Abnormalities of cerebellar foliation and fissuration: classification, neurogenetics and clinicoradiological correlates. Neuroradiology 44:639-646.
Depew M, Olsson L (2008): Symposium on the evolution and development of the vertebrate head. J Exp Zool 310B:287-293.

Edelman RR, Hesselink JR, Zlatkin MB (1996): Clinical Magnetic Resonance Imaging, ed 2. Philadelphia, Saunders, vol 1-2.

Galinsky V, Frank L (2014): Automated segmentation and shape characterization of volumetric data. NeuroImage 92:156-168.

Hall Z, Street S, Healy S (2013): The evolution of cerebellum structure correlates with nest complexity. Biol Lett 9:20130687.

Highstein SM, Thach WT (eds) (2002): The Cerebellum: Recent Developments in Cerebellar Research. New York, New York Academy of Sciences, vol 978.

Hoops D, Ullmann J, Janke A, Stait-Gardner T, Price W, Whiting M, Keogh S (2014): A 3D MRI-based atlas of a dragon brain. JB Johnston Club Evol Neurosci Annu Meet, Washington.

-Iwaniuk AN, Hurd PL, Douglas RWW (2006a): Comparative morphology of the avian cerebellum. 1. Degree of foliation. Brain Behav Evol 68:45-62.

Iwaniuk A, Hurd P, Wylie D (2006b): The comparative morphology of the cerebellum in caprimulgiform birds: evolutionary and functional implications Brain Behav Evol 67:5368.

Iwaniuk AN, Hurd PL, Wylie DRW (2007): Comparative morphology of the cerebellum. 2 . Size of folia. Brain Behav Evol 69:196-219.

Iwaniuk A, Lefebvre L, Wylie D (2009): The comparative approach and brain-behaviour relationships: a tool for understanding tool use. Can J Exp Psychol 63:150-159.

-Kaufman JA, Ahrens ET, Laidlaw DH, Zhang S, Allman JM (2005): Anatomical analysis of an aye-aye brain (Daubentonia madagascariensis, Primates: Prosimii) combining histology, structural magnetic resonance imaging, and diffusion-tensor imaging. Anat Rec A Discov Mol Cel Evol Biol 287:1026-1037.

Kazhdan M, Funkhouser T, Rusinkiewicz S (2003): Rotation invariant spherical harmonic representation of 3D shape descriptors; in Kobbelt L, Schroder P, Hoppe H, (eds): Symposium on Geometry Processing. Geneva, Eurographics, pp 156-164.

Larsell O (1967): The Comparative Anatomy and Histology of the Cerebellum from Myxinoids through Birds. Minneapolis, University of Minnesota Press.

Leto K, Arancillo M, Becker E, Buffo A, Chiang C, Ding B, Dobyns W, Dusart I, Haldipur P, Hatten M, Hoshino M, Joyner A, Kano M, Kilpatrick D, Koibuchi N, Marino S, Martinez S, Millen K, Millner T, Miyata T, Parmigiani E, Schilling K, Sekerková G, Sillitoe R, Sotelo C, Uesaka N, Wefers A, Wingate R, Hawkes R (2015): Consensus paper: cerebellar development. Cerebellum DOI: 10.1007/s12311-0150724-2.

Lisney TJ, Collin SP (2006): Brain morphology in large pelagic fishes: a comparison between sharks and teleosts. J Fish Biol 68:532-554.
Lisney TJ, Yopak KE, Montgomery JC, Collin SP (2008): Variation in brain organization and cerebellar foliation in chondrichthyans: batoids. Brain Behav Evol 72:262-282.

- Magnotta V, Andreasen N, Schultz S, Harris G, Cizadlo T, Heckel D, Nopoulos P, Flaum M (1999): Quantitative in vivo measurement of gyrification in the human brain: changes associated with aging. Cereb Cortex 9:151-160.

Marino L, Murphy TL, Deweerd AL, Morris JA, Fobbs AJ, Humblot N, Ridgway SH, Johnson JI (2001a): Anatomy and three-dimensional reconstructions of the brain of the white whale (Delphinapterus leucas) from magnetic resonance images (MRI). Anat Rec 262:429439.

Marino L, Sudheimer KD, Murphy TL, Davis KK, Pabst DA, McLellan WA, Rilling JK, Johnson JI (2001b): Anatomy and three-dimensional reconstructions of the brain of a bottlenose dolphin (Tursiops truncatus) from magnetic resonance images. Anat Rec 264:397-414.

- Marino L, Sudheimer K, Pabst DA, McLellan WA, Johnson JI (2003): Magnetic resonance images of the brain of a dwarf sperm whale (Kogia simus). J Anat 203:57-76.

Matochik J, Reems C, Wenzel B (1991): A brain atlas of the northern fulmar Fulmarus glacialis in stereotaxic coordinates. Brain Behav Evol 37:215-244.

Montgomery JC, Bodznick D, Yopak KE (2012): The cerebellum and cerebellar-like structures of cartilaginous fishes. Brain Behav Evol 80: 152-165.

Montie EW, Schneider G, Ketten DR, Marino L, Touhey KE, Hahn ME (2008): Volumetric neuroimaging of the Atlantic white-sided dolphin (Lagenorhynchus acutus) brain from in situ magnetic resonance images. Anat Rec 291:263-282.

New JG (2001): Comparative neurobiology of the elasmobranch cerebellum: theme and variations on a sensorimotor interface. Environ Biol Fish 60:93-108.

Nieuwenhuys R, Nicholson C (1969): A survey of the general morphology, the fiber connections, and the possible functional significances of the gigantocerebellum of mormyrid fishes; In Llinas R (ed): Neurobiology of Cerebellar Evolution and Development. Chicago, American Medical Association/Education Research Foundation, pp 107-134.

Northcutt RG (1977): Elasmobranch central nervous system organization and its possible evolutionary significance. Am Zool 17:411-429.

Northcutt RG (1978): Brain organization in the cartilaginous fishes; in Hodgson ES, Mathewson RF (eds): Sensory Biology of Sharks, Skates, and Rays. Arlington, Office of Naval Research, pp 117-194.

Northcutt RG (1989): Brain variation and phylogenetic trends in elasmobranch fishes. J Exp Zool Suppl 252:83-100.

Northcutt RG, Gans C (1983): The genesis of neural crest and epidermal placodes: a reinterpretation of vertebrate origins. Q Rev Biol 58:128. 
-Oelschlager HHA, Haas-Rioth M, Fung C, Ridgway SH, Knauth M (2008): Morphology and evolutionary biology of the dolphin (Delphinus sp.) brain: MR imaging and conventional histology. Brain Behav Evol 71:68-86.

-Oelschlager HHA, Ridgway SH, Knauth M (2010): Cetacean brain evolution: dwarf sperm whale (Kogia sima) and common dolphin (Delphinus delphis) - an investigation with high-resolution MRI. Brain Behav Evol 75:33-62.

Pearson R, Pearson L (1976): The Vertebrate Brain. London, Academic Press.

Pham D, Xu C, Prince J (2000): A survey of current methods in medical image segmentation. Annu Rev Biomed Eng 2:315-337.

Porrill J, Dean P, Anderson SR (2012): Adaptive filters and internal models: multilevel description of cerebellar function. Neural Netw 47:134-149.

- Pose-Méndez S, Candal E, Mazan S, RodríguezMoldes I (2015): Morphogenesis of the cerebellum and cerebellum-related structures in the shark Scyliorhinus canicula: insights on the ground pattern of the cerebellar ontogeny. Brain Struct Funct 221:1691-1717.

- Pose-Méndez S, Candal E, Mazan S, RodríguezMoldes I (2016): Genoarchitecture of the rostral hindbrain of a shark: basis for understanding the emergence of the cerebellum at the agnathan-gnathostome transition. Brain Struc Func 221:1321-1335.

-Pradel A, Langer M, Maisey JG, Geffar-Kuriyama D, Cloetens P, Janvier P, Tafforeau P (2009): Skull and brain of a 300-million-year-old chimaeroid fish revealed by synchroton holotomography. Proc Nat Acad Sci USA 106:52245228.

-Puzdrowski RL, Gruber S (2009): Morphologic features of the cerebellum of the Atlantic stingray, and their possible evolutionary significance. Integr Zool 4:110-122.

Puzdrowski RL, Leonard RB (1992): Variations in cerebellar morphology of the Atlantic stingray, Dasyatis sabina. Neurosci Lett 135:196200.

Senglaub K (1963): Das Kleinhirn der Vögel in Beziehung zu phylogenetischer Stellung, Lebensweise und Körpergrösse. Z Wiss Zool 169:1-63.

-Smeets WJAJ (1998): Cartilaginous fishes; in Nieuwenhuys R, Ten Donkelaar HJ, Nicholson C (eds): The Central Nervous System of Vertebrates. Berlin, Springer, pp 551-654.

Striedter GF (2005): Principles of Brain Evolution. Sunderland, Sinauer.
Sudarov A, Joyner AL (2007): Cerebellum morphogenesis: the foliation pattern is orchestrated by multi-cellular anchoring centers. Neural Dev 2:1-26.

-Sugahara F, Pascual-Anaya J, Oisi Y, Kuraku S, Aota S, Adachi N, Takagi W, Hirai T, Sato N, Murakami Y, Kuratani S (2016): Evidence from cyclostomes for complex regionalization of the ancestral vertebrate brain. Nature 531:97-100.

Sultan F (2005): Why some bird brains are larger than others. Curr Biol 15:R649-R650.

-Sultan F, Glickstein M (2007): The cerebellum: comparative and animal studies. Cerebellum 6:168-176.

- Thompson P, Schwartz C, Lin R, Khan A, Toga AW (1996a): Three-dimensional statistical analysis of sulcal variability in the human brain. J Neurosci 16:4261-4274.

Thompson P, Schwartz C, Toga A (1996b): Highresolution random mesh algorithms for creating a probabilistic 3D surface atlas of the human brain. Neuroimage 3:19-34.

Ullmann JFP, Cowin G, Collin SP (2010a): Magnetic resonance microscopy of the barramundi (Lates calcarifer) brain. J Morphol 271: 1446-1456.

Ullmann JFP, Cowin G, Collin SP (2010b): Quantitative assessment of brain volumes in fish: comparison of methodologies. Brain Behav Evol 76:261-270.

Ullmann JFP, Corwin G, Kurniawan ND, Collin SP (2010c): A three-dimensional digital atlas of the zebrafish brain. Neuroimage 51176-82.

- Van der Linden A, Verhoye M, Pörtner H-O, Bock C (2004): The strengths of in vivo magnetic resonance imaging (MRI) to study environmental adaptational physiology in fish. MAGMA 17:236-248.

Voogd J, Glickstein M (1998): The anatomy of the cerebellum. Trends Neurosci 21:370-375.

Voorhoeve (1917): Over den Bouw van de kleine hersenen der Plagiostomen; inaugural dissertation, University of Amsterdam, Amsterdam.

-Welker W (1990): Why does cerebral cortex fissure and fold? A review of determinants of gyri and sulci; in Jones EG, Peters A (eds): Cerebral Cortex: Comparative Structure and Evolution of Cerebral Cortex, Part II. New York, Plenum Press, pp 3-136.

Yopak KE (2012a): Neuroecology in cartilaginous fishes: the functional implications of brain scaling. J Fish Biol 80:1968-2023.

Yopak KE (2012b): The nervous system of cartilaginous fishes. Brain Behav Evol 80:77-79.
Yopak KE, Ainsley SM, Ebert DA, Frank LR (2010a): Exploring adaptive evolution in the brains of bathyal skates (family: Rajidae): phylogenetic and ecological perspectives. Brain Behav Evol 75:316.

Yopak KE, Balls G, Frank L (2009): Cortical Surface Structure Analysis in Sharks using Magnetic Resonance Imaging (MRI). Proc Int Soc Magn Reson Med 17:2925.

Yopak KE, Frank LR (2007): Variation in cerebellar foliation in cartilaginous fishes: ecological and behavioral considerations. Brain Behav Evol 70:210.

Yopak KE, Frank LR (2009): Brain size and brain organization of the whale shark, Rhincodon typus, using magnetic resonance imaging. Brain Behav Evol 74:121-142.

Yopak KE, Lisney TJ (2012): Allometric scaling of the optic tectum in cartilaginous fishes. Brain Behav Evol 80:108-126.

Yopak KE, Lisney TJ, Collin SP (2015): Not all sharks are 'swimming noses': variation in olfactory bulb size in cartilaginous fishes. Brain Struct Funct 220:1127-1143

- Yopak KE, Lisney TJ, Collin SP, Montgomery JC (2007): Variation in brain organization and cerebellar foliation in chondrichthyans: sharks and holocephalans. Brain Behav Evol 69:280-300.

Yopak KE, Lisney TJ, Darlington RB, Collin SP, Montgomery JC, Finlay BL (2010b): A conserved pattern of brain scaling from sharks to primates. Proc Nat Acad Sci USA 107:1294612951.

Yopak KE, Montgomery JC (2008): Brain organization and specialization in deep-sea chondrichthyans. Brain Behav Evol 71:287-304.

-Yushkevich PA, Piven J, Cody Hazlett H, Gimpel Smith R, Ho S, Gee JC, Gerig G (2006): Userguided 3D active contour segmentation of anatomical structures: significantly improved efficiency and reliability. Neuroimage 31: 1116-11128.

-Zeigler A, Faber C, Mueller S, Nagelmann N, Schroder L (2014): A dataset comprising 141 magnetic resonance imaging scans of $98 \mathrm{ex}$ tant sea urchin species. Gigascience 3:21.

Zhang Y, Shi Z, Magnus G, Meek J, Han VZ, Qiao JT (2011): Functional circuitry of a unique cerebellar specialization: the valvula cerebelli of a mormyrid fish. Neuroscience 182:11-31.

-Zilles K, Armstrong E, Moser KH, Schleicher A, Stephan H (1989): Gyrification in the cerebral cortex of primates. Brain Behav Evol 34:143150 